http://dx.doi.org/10.1590/1678-4162-9239

Arq. Bras. Med. Vet. Zootec., v.69, n.4, p.851-859, 2017

\title{
Novas perspectivas no diagnóstico e tratamento da acropostite-fimose em touros
}

\author{
[New perspectives in the diagnosis and treatment of acropostitis-phimosis of bulls] \\ R.E. Rabelo ${ }^{1}$, L.A.F. Silva ${ }^{2}$, N.C. Borges ${ }^{2}$, V.A.S. Vulcani ${ }^{1}$, R.S. Oliveira ${ }^{1}$, \\ G.P. Santos ${ }^{1}$, P.J.B. Queiroz ${ }^{2}$ \\ ${ }^{1}$ Universidade Federal de Goiás - UFG - Regional Jataí - Jataí, GO \\ ${ }^{2}$ Universidade Federal de Goiás - UFG - Escola de Veterinária e Zootecnia - Goiânia, GO

\section{RESUMO}

A acropostite-fimose é um processo inflamatório da extremidade do prepúcio, diagnosticada com frequência em touros. O presente estudo objetivou avaliar o exame ultrassonográfico na definição da viabilidade do folheto prepucial interno (FPI) e na evolução clínica do pós-operatório, após o emprego de fios de categute ou poliglactina na hemostasia e de algodão ou poliglactina na confecção de sutura padrão Donatti empregada para fixar o FPI à pele prepucial no transoperatório da acropostite-fimose em touros. A sutura utilizada foi captonada ou não captonada, e os animais submetidos ao procedimento cirúrgico apresentavam no mínimo dois terços do FPI viável. Os touros foram alocados, aleatoriamente, em quatro grupos contendo nove animais cada, de acordo com o fio empregado na hemostasia e na confecção da sutura padrão Donatti. O exame ultrassonográfico mostrou-se importante na indicação ou não do tratamento cirúrgico da acropostite-fimose e possibilitou localizar lesões, mensurar a área de reação tecidual e identificar lesões profundas e pontos de estreitamento do FPI. Os animais de GII apresentaram edema mais discreto, observando-se diferença significativa $(\mathrm{P}<0,05)$ entre GII e os grupos GI, GIII e GIV. A ocorrência de hiperemia no sétimo dia de pós-operatório também foi menor nos touros do grupo GII, ocorrendo diferença significativa $(\mathrm{P}<0,05)$ entre GII e os grupos GI e GIII. A sutura empregando o dispositivo de látex (cápton) e o emprego do fio de poliglactina apresentaram-se como medidas benéficas, resultando em menor número de complicações pós-operatórias.

Palavras-chave: bovino, cirurgia, exame clínico, prepúcio, reprodução

\begin{abstract}
Acropostitis-Phimosis is an inflammatory process of the extremity of the prepuce, frequently diagnosed in bulls. The present study aimed to evaluate ultrassound exams in the definition of viability of the internal layer of prepuce and the postoperative clinical evolution. This evaluation is after the employment of catgut or poliglactin threads in homeostasis, and cloth or polyglactin threads in confection of the standard suture, Donatti, used to fix the internal layer of prepuce to the preputial in the postoperative of acropostitis-phimosis in bulls. The suture was captonated and non-captonated and the animals conducted to the surgical procedure showed at least 2/3 of viability of the internal layer of prepuce. The bulls were randomly allocated in four groups, each one containing nine animals, according to the thread used in homeostasis and confection of the Donatti standard suture. Ultrassound was shown to be important in the indication or not of the surgical treatment of acropostitis-phimosis and allowed the identification of lesions, measurement of areas of tissue reaction and locate deep lesions and narrowing points of internal layer of prepuce. The employment of latex device (capton) in suture and the employment of polyglactin thread 910 were shown as beneficial measures, resulting in a lower number of postoperative complications.
\end{abstract}

Keywords: bovine, surgery, clinical examination, prepuce, reproduction

Recebido em 13 de junho de 2016

Aceito em 8 de setembro de 2016

E-mail: rabelovet@yahoo.com.br 


\section{INTRODUÇÃO}

A acropostite-fimose é um processo inflamatório localizado na extremidade do prepúcio de bovinos que pode resultar em impotência coeundi (Rabelo e Silva, 2011). Essa afecção tem predileção por touros com prepúcio penduloso, orifício prepucial largo e músculos prepuciais ausentes ou debilitados. Erros de manejo, controle inadequado de ectoparasitas, pastos com presença de ervas daninhas e plantas espinhosas, bicadas de aves de rapina ou domésticas e lesões parasitárias também favorecem o aparecimento dessa enfermidade (Fernandes et al., 2015). Raças zebuínas aparentemente são mais predispostas à enfermidade (Rabelo et al., 2008). Limitações ou inabilidade em efetuar a cópula, edema, necrose do folheto prepucial interno (FPI) prolapsado, miíases, hemorragia, fibrose, abscesso, hipertermia local e disúria são sinais clínicos observados (Rabelo et al., 2015). O diagnóstico da acropostite-fimose é fundamentado no histórico, em sinais clínicos e no exame clínico específico, mas a ultrassonografia percutânea é um método auxiliar importante no pré e pós-operatório da afecção (Noronha Filho et al., 2015).

Vários procedimentos cirúrgicos para o tratamento da acropostite-fimose foram descritos na literatura, porém os resultados são variáveis (Marques et al., 1988; Rabelo e Silva, 2011). O sucesso do procedimento deve-se, em parte, à observação do momento cirúrgico instituído após avaliação do processo inflamatório, à presença de ulcerações e à extensão da fibrose do FPI. Caso essas alterações comprometam dois terços do folheto prepucial interno (FPI), o procedimento cirúrgico torna-se inviável. As principais complicações observadas no pósoperatório de bovinos operados de acropostitefimose são comprometimento isquêmico do FPI, infecção, deiscência da ferida cirúrgica, retardo na cicatrização e fimose (Rabelo e Silva, 2011). Essas intercorrências, muitas vezes, estão relacionadas ao padrão de sutura e aos fios cirúrgicos inapropriados, pois predispõem à isquemia, à infecção e à adeiscência da ferida cirúrgica. Portanto, ao pesquisar novas perspectivas que minimizem tais complicações, é preciso buscar alternativas avançadas de diagnóstico e táticas operatórias que sejam simples, mas que possam proporcionar efeitos duradouros, aumentando a casuística recuperada.
O presente estudo objetivou avaliar o exame ultrassonográfico na definição da viabilidade do folheto prepucial interno (FPI) e na evolução clínica do pós-operatório, após o emprego de fios de categute ou poliglactina na hemostasia e de algodão ou poliglactina na confecção de sutura padrão Donatti empregada para fixar o FPI à pele prepucial no transoperatório da acropostitefimose em touros.

\section{METODOLOGIA}

O estudo foi realizado nos Setores de Cirurgia de Grandes Animais das Escolas de Medicina Veterinária e Zootecnia da Universidade Federal de Goiás, Regionais Jataí e Goiânia, ambas no estado de Goiás, no período compreendido entre fevereiro de 2010 a dezembro de 2013, totalizando 46 meses de avaliação. As intervenções cirúrgicas foram realizadas por professores de cirurgia de grandes animais das duas instituições de ensino, durante aulas práticas, execução de projetos de extensão, acompanhadas por alunos da graduação, residentes e alunos da pós-graduação. Foram utilizados 36 touros, distribuídos entre as raças Gir, Tabapuã, Guzerá, Santa Gertrudes, Nelore e Girolando, com idade variando entre 52 e 80 meses, portadores de acropostite-fimose. Todos os animais apresentavam, no mínimo, dois terços do folheto prepucial interno (FPI) viável. As atividades foram conduzidas com respaldo no parecer da Ceua/UFG, $\mathrm{N}^{\mathrm{o}} 150 / 2010$.

A viabilidade do folheto prepucial interno (FPI) foi confirmada mediante exame clínico específico da genitália externa e com o auxílio do exame ultrassonográfico. $\mathrm{Na}$ avaliação ultrassonográfica empregou-se o aparelho LOGIQ E (GE® - Fairfield, Merseyside) acoplado a um transdutor linear multifrequencial de 7,5 a $12 \mathrm{MHz}$, com frequência selecionada em $10 \mathrm{MHz}$. O exame iniciou-se com palpação da extremidade distal do pênis para identificação da porção livre do órgão, a qual foi usada como ponto de referência para a continuidade do exame. Avaliou-se, em cortes longitudinal e transversal, a qualidade dos tecidos adjacentes, a ecogenicidade, a ecotextura, a irrigação e a extensão da área comprometida. A capacidade de distensão do óstio prepucial foi avaliada por meio da injeção de solução salina a $0,9 \%$ e acompanhada em tempo real pelo ultrassom. 
Animais que apresentaram reações teciduais intensas envolvendo mais que dois terços do FPI foram descartados.

No pré-operatório, iniciado 72 horas antes da intervenção, realizou-se antibioticoterapia preventiva com $30.000 \mathrm{UI} / \mathrm{kg}$ de peso corporal de uma associação de penicilina (Penjet ${ }^{\circledR}$ Max, Clarion Biociências Ltda., Goiânia-GO), a cada 48 horas, por duas aplicações, e anti-inflamatório não esteroidal (AINE) à base de flunixina meglumina, por duas aplicações, a cada 24 horas (Flunxin $^{\circledR}$, Chemitec Agro-Veterinária, São Paulo-SP), bem como duchas com água sob pressão. Para a sedação dos animais, empregouse cloridrato de xilazina a $2 \%$ (Anasedan ${ }^{\circledR}$, Ceva - Sespo Ind. Com. Ltda., Paulínia-SP). Em seguida, os animais foram contidos em decúbito lateral direito e realizou-se higienização do prepúcio, antissepsia e bloqueio infiltrativo local com cloridrato de lidocaína a $2 \%$, sem vasoconstritor (Anestésico Bravet ${ }^{\circledR}$, Laboratório Bravet Ltda., Engenho Novo, RJ).

Em todos os procedimentos cirúrgicos, adotou-se a técnica descrita por Silva et al., (1998), que consistiu na circuncisão, no descolamento cirúrgico e no isolamento do folheto prepucial interno (FPI) do óstio prepucial (Fig. 1 A e B), seguido de incisão longitudinal praticada no folheto até a região limítrofe entre o tecido comprometido e o saudável. Após seccionar transversalmente o FPI e remover a porção lesionada, realizou-se a hemostasia, ligando-se os vasos sanguíneos principais. Procedeu-se, no FPI saudável, a incisões longitudinais equidistantes, resultando em uma figura semelhante a quatro "pétalas". Essa manobra teve a finalidade de compatibilizar os diâmetros do óstio prepucial com o diâmetro do FPI, para posterior aplicação de pontos de reparo em padrão Donatti, fixando-se, assim, as extremidades das "pétalas" do FPI ao óstio prepucial (Fig. 1 C). A síntese foi concluída mediante aplicação de vários pontos em padrão separado simples entre os vértices das "pétalas" e a extremidade do PFI.

Os touros foram alocados aleatoriamente em quatro grupos (GI, GII, GIII, GIV) contendo nove animais cada. A divisão dos grupos ocorreu de acordo com o fio empregado na hemostasia e nos pontos de reparo, os quais foram captonados ou não (Tab. 1). Nos grupos GII e GIII, empregaram-se cáptons de látex, que circundaram o fio do ponto de reparo aplicado para fixação do FPI ao óstio prepucial (Fig. $1 \mathrm{D}$ e E). O uso dos cáptons teve a finalidade de evitar o contato direto entre o fio e o FPI e entre o fio e a pele do óstio prepucial. Visando facilitar a remoção dos pontos, introduziu-se um fio de náilon $\mathrm{n}^{\circ} 1$ na luz de cada cápton em contato com a pele do óstio prepucial, e outro em contato com a luz do FPI.

Tabela 1. Distribuição dos grupos de touros submetidos à cirurgia de acropostite-fimose de acordo com o fio empregado na hemostasia e em pontos de reparo e o uso ou não de cáptons nos pontos de reparo

\begin{tabular}{clc}
\hline Grupo & \multicolumn{1}{c}{ Técnica cirúrgica } & $\mathrm{N}^{\circ}$ de animais \\
\hline \multirow{2}{*}{ GI } & $\begin{array}{l}\text { Hemostasia com categute } \mathrm{n}^{\circ} \text { 2-0. Pontos de reparo em padrão Donatti } \\
\text { com fio de algodão 000/não captonada }\end{array}$ & 09 \\
GII & $\begin{array}{l}\text { Hemostasia poliglactina } 910 \mathrm{n}^{\circ} \text { 2-0. Pontos de reparo em padrão } \\
\text { Donatti com fio de poliglactina } 910 \mathrm{n}^{\circ} \text { 2/captonada }\end{array}$ & 09 \\
GIII & $\begin{array}{l}\text { Hemostasia com categute } \mathrm{n}^{\circ} \text { 2-0. Pontos de reparo em padrão Donatti } \\
\text { com fio de algodão 000/captonada }\end{array}$ & 09 \\
& $\begin{array}{l}\text { Hemostasia com poliglactina } 910 \mathrm{n}^{\circ} \text { 2-0. Pontos de reparo em padrão } \\
\text { DIV }\end{array}$ & 09 \\
& Tonatti com poliglactina $910 \mathrm{n}^{\circ} 2 /$ não captonada $^{2}$ & 36 \\
\hline
\end{tabular}




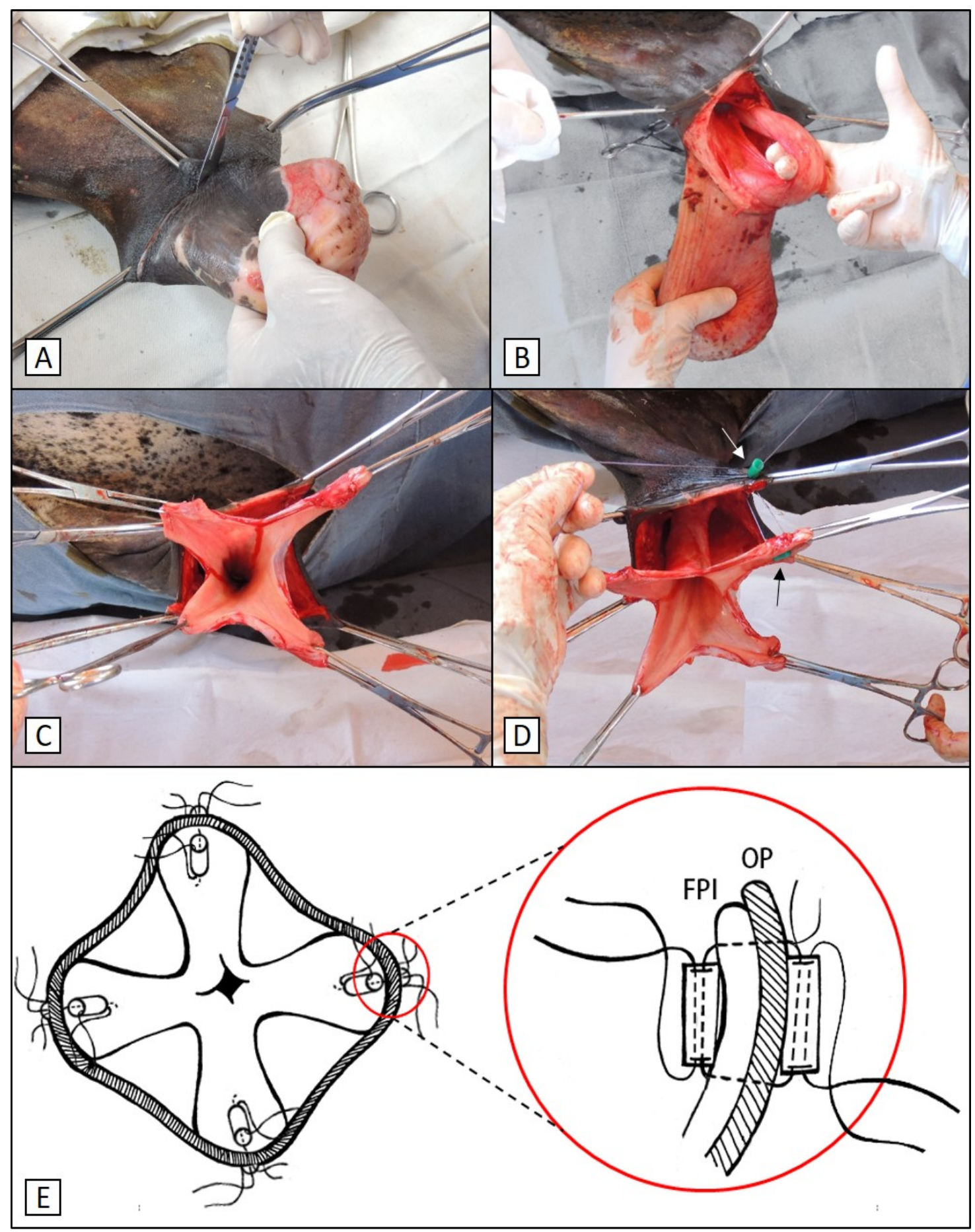

Figura 1. Tratamento cirúrgico da acropostite-fimose em touro. Em (A), delimitação da área do óstio prepucial a ser incisada empregando-se pinças de Kocher. Em (B), liberação do folheto prepucial interno (FPI) do óstio prepucial. Em (C), incisão longitudinal no FPI em forma de pétalas para compatibilidade de diâmetros. Em (D) emprego do dispositivo de látex, no FPI e na pele do óstio prepucial - OP (seta). Em (E), notar esquema evidenciando a sutura captonada em padrão Donatti e os fios introduzidos na "luz" do dispositivo para facilitar a remoção. 
O pós-operatório constou de antibioticoterapia utilizando-se o mesmo princípio ativo empregado no pré-operatório, totalizando três aplicações a cada 48 horas. Como terapia antiinflamatória, utilizaram-se três aplicações de flunixina meglumina a cada 24 horas. $\mathrm{O}$ uso da hidroterapia com água sob pressão, por 10 minutos, seguido de lavagem intraprepucial com solução de iodopovidona a $10 \%$, foi mantido por um período de 10 dias. Na sequência, aplicou-se dimetilsulfóxido - DMSO (DM-GEL $\AA$, Vetnil Ind. e Com. de Prod. Vet. Ltda., Brasil), circundando a extremidade prepucial, sem contato direto com a ferida cirúrgica. $\mathrm{Na}$ ferida, aplicou-se pomada auxiliar da cicatrização (Ganadol®, Zoetis, Ind. de Prod. Vet. Ltda., Brasil) até a reparação clínica se completar. O acompanhamento do pós-operatório ocorreu diariamente e por um período de 60 dias, e as complicações pós-cirúrgicas foram anotadas. Para a proteção da ferida cirúrgica, estabeleceuse como conduta o uso de cintas de suspensão confeccionadas em tecido de algodão tipo "avental" (Silva et al., 1994; Silva et al., 1998; Rabelo et al., 2008). Estas eram trocadas duas vezes ao dia na primeira semana de pósoperatório e, posteriormente, uma vez ao dia, sendo suspenso o emprego desse dispositivo protetor após 15 dias. Os pontos de reparo aplicados nos animais dos quatro grupos foram removidos no $14^{\circ}$ dia de pós-operatório.

A evolução clínica da ferida cirúrgica, independentemente do grupo, foi acompanhada diariamente, por meio de inspeção clínica. Todavia, para efeitos de descrição, consideraram-se os períodos de sete, 14, 21, 35, 45 e 60 dias após a realização dos procedimentos cirúrgicos. Foram avaliados aspectos como a presença de hemorragia, edema, hiperemia, exsudato no local dos pontos, necrose, deiscência parcial ou total da ferida, abscesso, tempo para a cicatrização completa, ausência de cura e recidiva da enfermidade. Os parâmetros edema, hiperemia e presença de exsudato no local dos pontos receberam uma nota de um a quatro, de acordo com a intensidade do processo: ausente (1), discreto (2), moderado (3) e grave (4). Esses parâmetros foram submetidos ao teste de Kruskal-Wallis ao nível de significância de 5\%.
Os demais parâmetros foram analisados por meio de estatística descritiva (Sampaio, 2010).

\section{RESULTADOS}

Durante 46 meses, foram atendidos 48 (100\%) touros apresentando acropostite-fimose. Desse total, $36(75 \%)$ foram submetidos ao tratamento cirúrgico, o equivalente a 1,05 caso por mês. Quanto aos 12 animais (25\%) não operados, em cinco (41\%), devido ao fato de a afecção não apresentar úlceras e fibrose, recomendou-se o tratamento clínico. Os sete $(59 \%)$ touros restantes foram descartados, em virtude de o comprometimento do folheto prepucial interno (FPI) por fibroses, úlceras e áreas de necrose atingir dois terços dessa estrutura anatômica. Dos 36 touros operados, oito eram Gir $(22,2 \%)$, quatro Tabapuã (11,1\%), um Guzerá $(2,7 \%), 21$ Nelore (58\%), um Santa Gertrudes (2,7\%) e um Girolando (2,7\%). Independentemente da raça, a maior ocorrência de acropostite-fimose foi observada entre 48 e 72 meses de idade.

O exame clínico específico, fundamentado na inspeção e palpação, e o exame ultrassonográfico foram fundamentais para se estabelecer a viabilidade do folheto interno prepucial (FPI). A ultrassonografia possibilitou localização da lesão, avaliação de sua extensão, mensuração da área de reação tecidual e identificação de pontos de estreitamento do diâmetro do FPI. O marco inicial do exame ultrassonográfico foi a identificação da uretra peniana na extremidade da glande (Fig. 2 A). Em seguida, foi feita uma varredura, movendo-se o transdutor no sentido do óstio prepucial e realizando-se cortes transversais e longitudinais. Essa manobra possibilitou a avaliação ultrassonográfica de toda a extensão do prepúcio, permitindo a identificação das características sonográficas dos tecidos adjacentes e a extensão da reação tecidual do FPI (Fig. 2 B).

A infusão de solução salina a $0,9 \%$ na luz prepucial promoveu o aumento no diâmetro do lúmen do FPI (Fig. 2 C), facilitando a avaliação da superfície luminal por meio da identificação de irregularidades (Fig. 2 D) e estreitamentos, especialmente nos cortes longitudinais. 

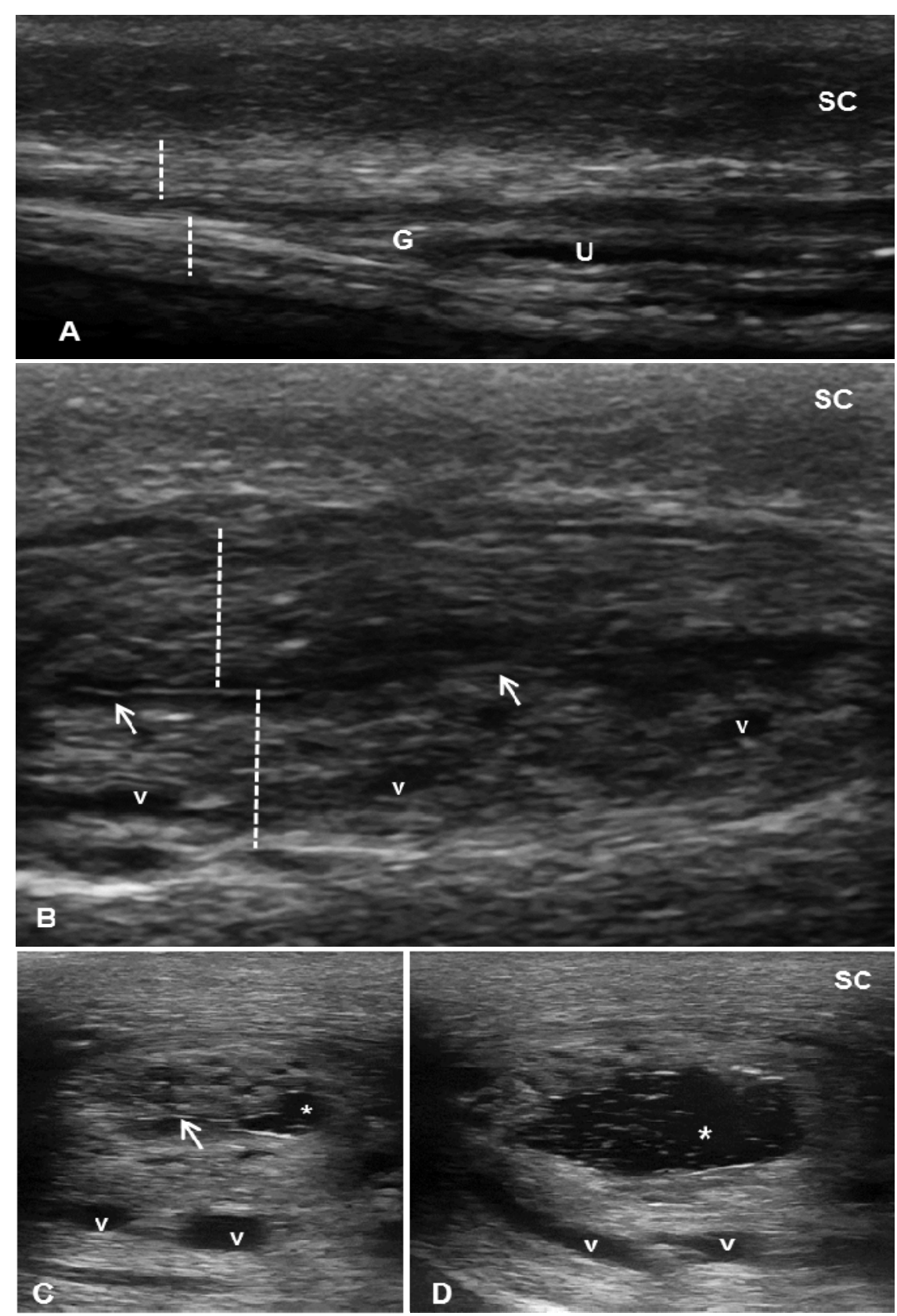

Figura 2. Ultrassonografia em cortes longitudinal (A e B) e transversal (C e D) do folheto prepucial de touros. Folheto prepucial com padrão de normalidade em (A) - ecogênico com linhas paralelas organizadas e espessura de $3 \mathrm{~mm}$ e reativo em (B) - ecogenicidade mista com perda na organização das linhas paralelas e espessura de $7 \mathrm{~mm}$. Distensão dos folhetos prepuciais produzida por líquido intraluminal (asterisco); notar as mucosas (seta branca) em fase de expansão (C) e em completa expansão produzida pelo líquido infundido com pontos hiperecoicos em suspensão (D). Glande (G), uretra peniana (U), vasos sanguíneos (v) anecoicos, tecido subcutâneo (SC) ecogênico.

As médias e medianas dos parâmetros edema, hiperemia e exsudato são representadas na Tab. 2. Todos os animais apresentaram algum grau de edema prepucial aos sete dias de pós-operatório, entretanto os animais de GII apresentaram edema mais discreto, observando-se diferença significativa $(\mathrm{P}<0,05)$ entre GII e os grupos GI, GIII e GIV. Não houve diferença significativa 
$(\mathrm{P}<0,05)$ quanto à intensidade do edema no sétimo dia de avaliação entre os grupos GI e GIII e os grupos GIII e GIV. Após esse período, houve em todos os grupos uma tendência de redução gradativa do edema, de forma que, aos 14 dias de pós-operatório, nenhum grupo diferiu significativamente $(\mathrm{P}<0,05)$ quanto à intensidade do edema prepucial.

Tabela 2. Valores de média e mediana para os parâmetros edema aos sete e 14 dias de pós-operatório, hiperemia aos sete dias de pós-operatório e exsudato aos 14 dias de pós-operatório

\begin{tabular}{|c|c|c|c|c|c|}
\hline \multirow{2}{*}{ Parâmetro } & \multicolumn{4}{|c|}{ Grupos } & \multirow{2}{*}{$\begin{array}{c}\text { P (Kruskal- } \\
\text { Wallis) }\end{array}$} \\
\hline & GI & GII & GIII & GIV & \\
\hline Edema (7 dias) & $3,4(4) a$ & $2(2) c$ & $2,8(3) a b$ & $2,5(2) b$ & 0,0007 \\
\hline Edema (14 dias) & $1,2(1) a$ & $1(1) a$ & $1,1(1) a$ & $1(1) \mathrm{a}$ & 0,2737 \\
\hline Hiperemia (7 dias) & $3,3(3) a$ & $2,1(2) \mathrm{c}$ & $2,8(3) a b$ & $2,4(2) b c$ & 0,0048 \\
\hline Exsudato (14 dias) & $3,4(4) a$ & $1,2(1) b$ & $2,8(3) a$ & $1,6(2) b$ & 0,0001 \\
\hline
\end{tabular}

Médias e medianas seguidas da mesma letra nas linhas não apresentam diferença estatística $(\mathrm{P}<0,05)$.

A ocorrência de hiperemia no sétimo dia de pósoperatório também foi menor nos touros do grupo GII, ocorrendo diferença significativa $(\mathrm{P}<0,05)$ entre GII e os grupos GI e GIII. Os grupos GII e GIV, GI e GIII, GIII e GIV não apresentaram diferença significativa $(\mathrm{P}<0,050)$ quanto à intensidade da hiperemia. Nas demais avaliações, não houve presença de hiperemia digna de nota em nenhum dos grupos. A ocorrência de exsudação nas regiões de aplicação dos pontos de Donatti foi observada somente no $14^{\circ}$ dia de avaliação. Nesse parâmetro, os animais de GII e GIV apresentaram menor grau de exsudação, ambos diferindo estatisticamente $(\mathrm{P}<0,05)$ de GI e GIII.

Mesmo adotando rigorosa higienização, antissepsia e curativos da ferida cirúrgica, em dois $(22,2 \%)$ touros de GI a infecção evoluiu para formação de abscesso, sendo este observado em uma das avaliações no período compreendido entre o $14^{\circ}$ e o $21^{\circ}$ dia de avaliação clínica. Foi necessária drenagem cirúrgica do abscesso. A deiscência parcial da ferida e a necrose em alguns pontos da lesão foram verificadas em dois segmentos do FPI, sendo essas intercorrências constatadas em um $(11,1 \%)$ touro de GI no $21^{\circ}$ dia de pós-operatório. $\mathrm{O}$ animal foi avaliado e considerado, ao final da avaliação clínica, como não recuperado.

No $14^{\circ}$ dia pós-cirúrgico, por ocasião da remoção dos pontos de reparo, notou-se, em dois touros $(22,2 \%)$ alocados em GII e em um $(11,1 \%)$ touro do GIII, certa dificuldade em remover o cápton, pois os dispositivos se apresentaram parcialmente envolvidos pelo FPI. Apesar dessa dificuldade técnica, não se observaram outras implicações importantes no local em que os dispositivos foram aplicados. A aplicação do cápton de látex nos pontos de reparo de Donatti nos animais alocados em GII e GIV não resultou em aumento do tempo operatório, e o uso de um fio de náilon inserido na luz do cápton evitou o sequestro desse dispositivo pela FPI, facilitando sua retirada.

Aos 35 dias de pós-operatório, nove (100\%) dos touros de GII e seis $(66,6 \%)$ de GIV foram considerados recuperados, estando a ferida cicatrizada em sua plenitude. $\mathrm{O}$ folheto prepucial interno (FPI) apresentava aspecto rosado, similar à coloração natural, sem evidências de injúrias, contaminação ou rejeição ao fio. Todavia, o repouso sexual de 90 dias ainda prevaleceu. Aos 45 dias de pós-operatório, os outros três $(33,3 \%)$ touros de GIV, que ainda não haviam sido considerados recuperados, apresentaram cura completa. Nesse período, a ferida apresentou-se totalmente cicatrizada somente em seis $(66,6 \%)$ touros de GI e quatro $(44,4 \%)$ de GIII, sendo necessária, nos dois $(22,2 \%)$ animais de GI e em cinco $(55,5 \%)$ de GIII, a continuidade das condutas de curativos prescritas. Nesses animais, a cicatrização e a consequente cura clínica ocorreram entre o período da última avaliação, aos 60 dias. Um touro de GI foi considerado não recuperado.

\section{DISCUSSÃO}

A maior ocorrência de acropostite-fimose em touros Bos indicus observada neste trabalho demonstra que a morfologia do prepúcio tem uma relação estreita com a afecção. Como algumas linhagens das raças Gir, Tabapuã, Guzerá e Nelore apresentam prepúcios pendulosos acompanhados de prolapso do 
folheto interno prepucial (FPI), pode-se inferir que essas características são fatores de risco para o problema. Tais particularidades, associadas à expressiva população de animais da raça Nelore nos diferentes criatórios, justificam, em parte, os $58 \%$ de bovinos operados dessa raça. Segundo Rabelo e Silva (2011), bovinos portadores de orifício prepucial largo, prepúcio penduloso, com músculos prepuciais ausentes ou debilitados, em associação à negligência sanitária e a erros de manejo, explicam por que algumas raças são mais acometidas pela enfermidade.

Dos 36 animais operados, 35 (97,22\%) apresentaram recuperação total. $\mathrm{O}$ sucesso do tratamento cirúrgico pode ser atribuído, em parte, à escolha correta do momento cirúrgico. A intensidade do processo inflamatório, a presença de úlceras e fibroses, a necrose e as miíases no FPI nortearam a definição do momento cirúrgico e foram fundamentais para se estabelecer o protocolo terapêutico ou recomendar o descarte do animal. Além disso, a realização de terapia pré-operatória visando reduzir o processo inflamatório prepucial e a experiência dos cirurgiões foram fatores relevantes para $o$ sucesso do tratamento cirúrgico.

O exame ultrassonográfico também se apresentou como uma alternativa importante para a definição do momento cirúrgico, pois foi fundamental para se estabelecer a localização das alterações, determinar a dimensão das lesões, o diâmetro da luz do FPI e as características da reação tecidual circundante. Portanto, o uso do exame ultrassonográfico permitiu definir quais animais apresentavam maiores chances de recuperação e possibilitou, também, maior segurança na escolha quanto ao tratamento clínico ou cirúrgico. $\mathrm{Na}$ literatura consultada, apenas Noronha Filho et al. (2015) empregaram o exame ultrassonográfico na avaliação do prepúcio, mas não apontaram as vantagens de se utilizar esse exame na avaliação de touros com acropostite-fimose. Outros autores, quando avaliaram testículos de touros, enfatizaram a importância da ultrassonografia como método complementar de diagnóstico de intercorrências como fibrose, aderências, inflamações, abscessos, entre outras, dando sustentação técnica à metodologia empregada no presente estudo (Gnemmi e Lefebvre, 2009; Cardilli et al., 2012; Kastelie e Brito, 2012).
Quanto ao parâmetro edema aos sete dias de pósoperatório, observou-se que o GII apresentou edema menos intenso em comparação aos demais grupos. Esse resultado pode ser justificado pela menor reação inflamatória tecidual promovida pelo fio de poliglactina $910 \mathrm{em}$ associação ao cápton de látex. $\mathrm{O}$ cápton evitou o contato direto do fio com o FPI, minimizando a pressão exercida pelo fio sobre o tecido e, consequentemente, reduzindo a irritação tecidual, o processo inflamatório e o edema. Apesar disso, observou-se diferença significativa quanto à intensidade do edema somente na primeira semana de pós-operatório, indicando que, na segunda semana após a cirurgia, a inflamação apresenta redução gradativa, independentemente do fio e do uso do dispositivo de cápton.

Nos grupos GI e GIII, nos quais se utilizou fio de categute para hemostasia e fio de algodão para os pontos de reparo, observou-se maior intensidade de reação inflamatória e exsudação. Esse fato pode ter ocorrido, pois o fio de algodão é constituído de celulose e caracteriza-se por ser multifilamentar e possuir alto grau de absorção, facilitando o acúmulo de líquidos e, consequentemente, a multiplicação bacteriana (Soares et al., 2001). Além disso, o mecanismo de absorção do fio de categute é mediado por uma intensa reposta celular, que promove a liberação de colagenases e proteases, as quais realizam a degradação do fio (Benicewicz e Hopper, 1990). Essa resposta celular intensa envolve maior processo inflamatório e, em decorrência disso, edema e hiperemia mais intensos. Ainda que seja um fio absorvível sintético multifilamentar, o fio de poliglactina 910 é degradado por hidrólise, promovendo uma reação inflamatória de baixa intensidade e, como consequência, um processo de reparo mais favorável (Saito et al., 2006; Kudur et al., 2009). Acrescente-se que a ocorrência de abscesso em dois touros pertencentes ao GI, mesmo se utilizando técnicas de antissepsia e cuidados pósoperatórios idênticos em todos os grupos, está relacionada possivelmente às características do fio de algodão, que potencializam os riscos de infecção bacteriana, conforme observado por Maldonado et al. (2006).

Apesar da ocorrência de alguma dificuldade para se remover o cápton nos primeiros animais operados, o uso de um fio de náilon inserido na sua luz foi essencial para se evitar o sequestro 
desse dispositivo pela FPI e facilitar sua retirada. Como não se observoaram outras implicações no local em que os dispositivos foram aplicados, os resultados permitem recomendar o dispositivo nos pontos de reparo aplicados na cirurgia de acropostite-fimose. À semelhança do observado neste estudo, Fernandes et al. (2015), ao avaliarem 12 reprodutores empregando técnica similar à utilizada em GII, atestaram que o dispositivo diminuiu o número de complicações, particularmente infecção e deiscência da ferida cirúrgica, fato este também citado por Rabelo e Silva (2011).

\section{CONCLUSÕES}

Concluiu-se que o exame ultrassonográfico se mostrou importante na caracterização da lesão, na determinação do momento cirúrgico e na avaliação de complicações pós-operatórias decorrentes do tratamento cirúrgico da acropostite-fimose em touros. A sutura empregando o dispositivo de látex (cápton) e o emprego do fio de poliglactina 910 apresentaram-se como medidas benéficas na correção cirúrgica da acropostite-fimose, resultando em menor número de complicações pós-operatórias e propiciando uma cicatrização mais rápida.

\section{REFERÊNCIAS}

BENICEWICZ, B.C.; HOPPER, P.K. Review: polymers for absorbable surgical sutures-part 1. J. Bioact. Compat. Polym., v.5, p.453-472,1990.

CARDILLI, D.J.; TONIOLLO, G.H.; PASTORE, A.A. et al. Ultrassonografia testicular em bovinos jovens da raça Nelore criados em sistema extensivo. Arq. Bras. Med. Vet. Zootec., v.64, p.75-82, 2012.

FERNANDES, J.P.B.; RABELO, R.E.; VULCANI, V.A.S. et al. Epidemiologia de enfermidades acometendo a genitália externa de touros no estado de Goiás. Biológico, v.77, Supl.2, p.123, 2015.

GNEMMI, G.; LEFEBVRE, R. C. Ultrasound imaging of the bull reproductive tract: an important field of expertise for veterinarians. Vet. Clin. N. Am. Food. Anim. Pract., v.25, p.767-779, 2009.

KASTELIC, J.P.; BRITO, L.F.C. Ultrasonography for monitoring reproductive function in the bull. Reprod. Domest. Anim., v.47, Supl.3, p.45-51, 2012.
KUDUR, M.H.; PAI, S.B.; SRIPATHI, H. et al. Sutures and suturing techniques in skin closure. Indian. J. Dermatol. Venereol. Leprol., v.75, p.425434, 2009.

MALDONADO, F.; MUÑOZ, L.; QUEZADA, M. et al. Reacción tisular a materiales de sutura no absorbibles em piel de equinos. Arch. Med. Vet., v.38, p.63-67, 2006.

MARQUES, J.A.; MARQUES, L.C.; CANOLA, J.C. et al. Acropostite-fimose em touros - uma técnica cirúrgica de tratamento. Ciên. Vet., v.2, p.2-3, 1988.

NORONHA FILHO, A.D.F.; BORGES, N.C.; FREITAS, S.L.R. et al. Ultrassonografia do prepúcio de touros com acropostite e fimose - resultados parciais. Biológico, v.77, Supl.2, p.9, 2015.

RABELO, R.E.; SILVA, O.C. Aspectos morfofuncionais, clínicos e cirúrgicos do pênis, prepúcio e testículos de touros. Goiânia: Kelps, 2011. $211 \mathrm{p}$.

RABELO, R.E.; SILVA, L.A.F.; BRITO, L.A.B. et al. Epidemiological aspects of surgical diseases of the genital tract in a population of 12.320 breeding bulls (1982-2007) in the state of Goias, Brazil. Ciên. Anim. Bras., v.9, p.707-713, 2008.

RABELO, R.E.; VULCANI, V.A.S.; ASSIS, M.B. et al. Necrose da extremidade livre do pênis como complicação de acropostite-fimose em touro. Encicl. Bios, v.11, p.2296-2303, 2015

SAITO, C.T.M.H.; BERNABÉ, P.F.E.; OKAMOTO, R. et al. Reação do tecido conjuntivo subcutâneo de ratos aos fios de sutura poliglecaprone 25 (monocryl) e poliglactina 910 (vicryl). Salusvita, v.26, p.27-38, 2006.

SAMPAIO, I.B.M. Estatística aplicada a experimentação animal. 3.ed. Belo Horizonte: FEPMVZ, 2010. 550p.

SOARES, U.N.; ITO, I.Y.; BARROS, V.M.R. Efeito da anti-sepsia da ferida cirúrgica alveolar sobre o crescimento bacteriano em fios de sutura de algodão. Pesqui. Odontol. Bras., v.15, p.41-46.

SILVA, L.A.F.; FIORAVANTI, M.C.S.; ACYPRESTE, C.S. et al. Tratamento cirúrgico da estenose e/ou fibrose prepucial em touros. ARS Vet., v.14, p.235-244, 1998.

SILVA, L.A.F.; FIORAVANTI, M.C.S.; BORGES, N.C. et al. Utilização do avental como auxiliar no pósoperatório da acrobustite ou acropostite-fimose. An. Esc. Agron. Vet., v.24, p.142-147, 1994. 